\title{
3. DEVELOPING BY DRAWING CREATIVITY OF CHILDREN ACTIVITIES
}

Felicia Ceauşu ${ }^{260}$

\begin{abstract}
The potential creativity elements can be expressivity, flexibility, fluency, brain sensibility as well as the qualities of the analyzers and temperamental characteristics which have an important role in triggering, developing and manifesting creativity. Here we must also take into account the relationship of the subject with the environment and educational factors. For the child, creativity has certain time limits that are determined by a multitude of factors such as: adaptation to new changes, will, creative type cognitive type, the feeling of duty and responsibility, ideal, surrounding atmosphere. In the current paperwork, we aimed to elevate the development level of creativity by plastic arts and we remarked that, in those plastic art activities where the basic method was the play, the efficient organization of the activities of plastic arts. The child is an active subject of knowledge who absorbs with lust the information proposed by the educator, he/she must be ready to receive more and more knowledge. The main task of the adults is to create optimal conditions of discovery and achievement of his/her creative possibilities and to take into consideration the individuality of each child.
\end{abstract}

Key words: creativity, expressivity, flexibility, fluency, cognitive interest

\section{Conceptual delimitations}

Creativity represents an extraordinary modern face but not enough known and harnessed. H. Jaoui, defining creativity as "an ability to carry out original and efficient assemblies starting from pre-existing elements", considers that anyone can be creative" 261 (1990). The term of creativity is used in relation with three aspects. Creativity is evidenced firstly in relation with the action, the creation process, a phenomenon of extreme personality through which it is created either an artwork or a technical innovation, a mechanism, a device. The result of the creating process is explained by the creativity of a person by a complex ability of the human being, a characteristic structure of the psyche enabling the creating work. Finally, creativity is also objectively estimated by the activity product - more or less remarkable, new, original.

However, it would be wrong if we would identify superior intelligence with creativity as it is defined by the originality and value of the created products. In other words, "superior intelligence does not mean by all means creativity" 262 (Landau), since not all intelligent people are also creative. „Although the research in the field of creativity was intensified only in 1950 with studies since 1926, G. Wallace set out the phases of the creation process: training, incubation, illumination (inspiration) and verification. In 1971, A. Moles and R. Claude

\footnotetext{
260 Researcher PhD, Romanian Academy, Institute "Gh. Zane” from Iași Branch of Romania, email: ceausufelicia@yahoo.com

${ }^{261}$ Jaoui, H., (1998), La creativité, ESF, Paris, p.90

${ }^{262}$ Popescu, Gabriela, (2007), Psychology of Creativity, Fundaţia România de Mâine Print House, Bucharest, p.59
} 
distinguished five stages: informing and documentation, incubation, illumination, verification and formulation.,"263

\section{Psychic-educational bases of developing creative abilities}

Creativity, in the broadest sense, represents that complex ability of the human being, that characteristic structure of the psyche that makes possible the creating work. L. Taylor talks about the five levels of creativity among which, at the preschool age, the only level that can be achieved is the one of expressive creativity. This type of creativity is characterized by a free and spontaneous expression of the person without being concerned for the product of its activity to have a certain degree of utility or value (e.g. drawing, collage, modeling activities etc). The preschool years are more and more appreciated as a period that contains the most important education experience from the life of a person; during it we record the most pregnant rhythms regarding the development of human individuality and some of the most significant gains with obvious echoes for the later stages of its development." 264 At this age, creation, even if has no value of the "humankind", is extremely important for the "human becoming" of the child. The adult man cannot reach to higher forms of expressing creativity if, in the early stages of its evolution, he/she did not develop the creative potential, was not encouraged to have independent and original manifestations in answers and solutions to the issues occurred in childhood and adolescence.

The psychological profile of the pre-school age includes many favoring conditions for the cultivation and stimulation of the creative potential. Considering the dynamism, impetuosity and expressivity specific to that age, this permanent excitement or that vibration and inner effervescence confers to the children specific notes of creative dynamism, chances of spontaneous exteriorization and vivid auto-expression, analogue to any creating upsurge. The receptivity and curiosity of the child, the richness of the imagination, his/her spontaneous tendency towards novelty, the passion for fable, his/her desire to create something constructive, the psycho-social climate or atmosphere in which the activity of the child is carried out can be "fueled" and adequately harnessed by requests and corresponding training that thus may be able to offer multiple positive elements in stimulating and cultivating the creative potential specific to the pre-school age. At the pre-school age, the child has the tendency to express in his/her works based on personal experience. Thus it is a good practice to give to the child the freedom of ideas, to find means and forms of presenting own impressions about the world in which to reflect the felt emotions and feelings.

The artistic-plastic activities are a way of activating and expressing the child's life. "The motivation of the child for artistic-plastic activities represents the need of expression of own experiences, the need to render the image in an artistic way or the pleasure to narrate in images. The plastic representations of the child gradually evolve towards a more realistic rendering, sometimes the creating imagination intervenes and pass towards fabulous, towards the

\footnotetext{
${ }^{263}$ Munteanu, A.,(1994), Incursions in Creatology, August Print House, Timişoara, p.110

${ }^{264}$ E., Rafailă, (2001), Education of creativity at the pre-school age. Bucharest: Aramis Print House, p.91
} 
unreal."265 The children of pre-school age create with carefulness and competence, under the close guidance of the teacher, original, peculiar but mainly interesting works by the multitude of used materials and working techniques.

The various types of practical and plastic activities are very beloved and attracting for the children. Through them, pre-school children come into contact with some simple forms of physical and intellectual work allowing both the development of the physical abilities of the children as well as the intellectual ones. By carrying out practical and plastic activities we can educate and development many psychic processes (perception, representations, observation, attention, memory, thinking, imagination) and some qualities related to personality are laid: initiative, confidence in own abilities, desire to work in a group, creativity.

For the pre-school age, there are numerous and varies plastic and practical activities, taking into account the particularities of development specific to each level of age as well as the grading of difficulties of the tasks leading to the concretization of the proposed topics. At the pre-school age, the techniques that may be used in artistic-plastic activities as well as in practical activities are as follows:

- technique of the thread;

- technique of stamping;

- technique of wet colors;

- technique of the ink spot;

- technique of the air jet;

- technique of finger painting ;

- technique of the drawing with candle;

- drawing with chalk, correction fluid, tempera, watercolor;

- technique of the modeling;

- technique of the collage etc.

Strengthening and broadening of elementary knowledge regarding the plastic language, obtaining the plastic image through dots, lines, spots, observing some requirements of: rendering the general shape of each component part, in details, placing the elements in space, rendering of some spatial relationships by higher or lower placing on the plane surface as well as covering of more distant objects by the nearer ones; creation of visual balance, harmonious joining of shapes and colors, initiations in notions of compositions, sketch. „The orientation of the practical activity process of the children towards the representation of own feelings, attitudes, finding own means of representation, improving the graphical skills related to execution that the child has by hachuring in various directions, tracing as perfect as possible straight, inclined, parallel, wavy, rounded lines; getting thin, thick, light, pronounced lines in order to enhance the artistic effect, removing of useless lines, tinting and highlighting shapes." ${ }^{266}$ The skills of handling and selection of necessary

${ }^{265}$ BODEN, A., (1995), The Creative Mind: Myths and Mechanism. New York: Basic Books, p.343

${ }^{266}$ FUSTIER, M., FUSTIER, Bernardette, (1988), Pratique de la Créativité. Paris: ESF, ed. A II.a, p.178 
materials and tools (simple and colored crayons, markers, pastel crayons, nib, pen, burnt sticks, chalk, brick etc.).

„It is important to develop in children the desire to carry out something new but this may be done based on diversity. The familiarization of children with some new working techniques enhances their curiosity and determines the artistic-plastic activities to be attractive and creative." 267 Regarding evaluation, the artistic-plastic and practical activities involve a complex analysis since they are referring both to the product of the children's work and to the knowledge regarding its materials and characteristics as well as to the use of working techniques specific to age for its processing and creating some simple products but also to an analysis of the children's behavior and attitude towards their own creations. The advantages of carrying out plastic activities in pre-school children: - Developing of esthetic sensitivity, contribution in forming the artistic taste via the means of painting expression (colors, light and brightness, spot, line, dot).

- Training of presentation skills (by the plastic language) of own ideas, feelings, experiences, moods via colors, shapes, their proportions etc.

- Familiarization with the constructive and spatial role of the line, dot, spot, skills of line modeling (uniform, of various thicknesses, straight, vertical, horizontal, inclined, parallel, intersected, curve, wavy, rounded etc).

- Development of the ability to combine colors and to apply them in own creations, highlighting both the specificity of those represented as well as the emotional state (joy, tranquility, anxiety etc), harmonious and balanced distribution of cold and warm colors.

- Familiarization of children with the working materials and tools (brushes, watercolor painting, gouache, some natural colorants, palettes etc) working way with these.

- Development of observation, visual memory, motion.

- Consolidation of skills related to representation of ornamental motives; initiation in the stylizing ways of shapes, their harmonious combinations.

The drawing activities have a multilateral influence on children. They mainly bring a significant contribution in the field of esthetic education. With the help of drawing activities, the children gain some elementary skills and abilities to render in artistic images the reality, to combine lines, shapes colors etc so that to obtain artistic effects. „The development of the child's thinking and imagination is another field in which the influence of drawing activities is manifested. These activities confer the possibility to carry out operations of analysis, synthesis, comparisons and generalizations." 268 Drawing any object, the children must consider its components parts and their attributes; to compare these parts between them in order to create images as close as the reality; also, they are in the position to mirror the essential features of some categories of objects, beings etc, to generalize.

\footnotetext{
${ }^{267}$ ROCO, Mihaela, (2004), Emotional Creativity and Intelligence. Polirom Print House, Iaşi

${ }^{268}$ G., Kelemen, (2007), Pre-school Education, ,Aurel Vlaicu” University Print House of Arad, p.112
} 
Beginning the early age, we may use these means, the color being the first notion that is assimilated; based on color the child can tell what object he/she drew. Through color, a series of object phenomena are rendered. At the age of 67 years the children know the basic colors and apply them in practice. The nuances likewise, by combining more colors which creates a nuance. As the child perceives these nuances from one and the same color this means that his/her sensorial perception is more developed (yellow - red, yellow - brown), what color do we have? The child must be taught how to combine and to mix. By explanation, demonstration, the child cannot be taught but only by practical activity. By mimics, he/she speaks about aggressiveness, by color we may render the psychological state of a being. The child must know the warm, color, neutral colors. The flower bouquet in warm, cold, neutral colors. The children use the simple pencil, aquarelles, charcoal pencil, colored chalk, wax pencil; a tree may be represented, the sky, the soil, a strip, a large surface, the joyful and beautiful spring. The shape plays a very important role regarding expressivity the child most oftene use the square, the circle, the triangle, all geometrical shapes, arches, plates. They render only plane images.

\section{Conclusions}

The pre-school age is a determining stage. Flexibility, fluency, imagination, ingenuity, high sensitivity at this age determines the potential possibilities of the multilateral development of the child. The results of children at the pre-school age serve as a basis of success in later school grades. At the end of the pre-school age in children, the desire to learn must persist, he/she must know to correctly learn and to have confidence in his/her own strengths. The child is an active subject of knowledge absorbing with lust the information which the educator proposes that he/she must be prepared to receive more and more knowledge. The main task of the adults is to create optimal conditions of discovery and achievement of his/her creative possibilities and to take into account the individuality of each child.

From the point of view of forming the personality, creativity acquires the purpose of creative potential, the sum of qualities or psychic factors of the future creative performance ${ }^{1}$. All virtual conditions existing in the human being, and not necessarily the used ones, that can contribute to the success of the creative act, make up the potential creativity of the person compared to the creative ability which implies the real "updated possibility" of creation. The potential creativity is in fact the performance obtained at the creativity tests. In fact, creativity may mean either an ability or a skill of the "person" as A. Roşca indicates, e.g. to make up original and useful ideas or things both as an action and process that lead to the original product, the latter being considered, on its turn, as a criterion of creativity.

The task of the teacher is to educate and find out the creative abilities of the pre-school child. Education and stimulation of the child's creativity implies knowing their creative potential, finding out the intellectual, skill and personality related factors that, by interaction and overlapping, provides this potential. Even though we cannot discuss yet some well outlined and, at the 
same time, accessible techniques and methods, the teacher may use, with good results, the classical methods of knowing the child (observation, dialogue etc). To these we may add various tests of creativity and divergent thinking.

\section{References}

1. Boden, A. (1995). The Creative Mind: Myths and Mechanism. New York: Basic Books

2. Fustier, M., Fustier, B. (1988). Pratique de la Créativité (second edition). Paris: ESF

3. Jaoui, H. (1998). La creativité. Paris: ESF

4. Kelemen, G. (2007). Pre-school Education. Arad: Aurel Vlaicu University Print House

5. Munteanu, A. (1994). Incursions in Creatology. Timişoara: August Print House

6. Popescu, G. (2007). Psychology of Creativity. București: Fundaţia România de Mâine Print House

7. Rafailă, E. (2001). Education of creativity at the pre-school age. București: Aramis Print House

8. Roco, M. (2004). Emotional Creativity and Intelligence. Iaşi: Polirom Print House 